\title{
Ecology, Distribution and Risk of Transmission of Viral Haemorrhagic Fevers by Aedes Mosquitoes around the Port Areas of Tema in Southern Ghana
}

\author{
Kenechukwu C. Ojukwu1, Joseph Chabi' ${ }^{2}$, Kwadwo Frempong2, Delphina A. Adabie-Gomez ${ }^{1,3}$, \\ Joseph Harold Nyarko Osei ${ }^{2}$, Andy Asafu-Adjaye ${ }^{2}$, Sellase Pi-Bansa ${ }^{2}$, Michelle Adimazoya², \\ Kojo Y. Sakyi2, Kwaku O. Akuoko², Ruth Brenyah4, Maxwell A. Appawu², \\ Samuel Kweku Dadzie1,2* \\ ${ }^{1}$ African Regional Postgraduate Programme in Insect Science, University of Ghana, Accra, Ghana \\ ${ }^{2}$ Parasitology Department, Noguchi Memorial Institute of Medical Research, University of Ghana, Accra, Ghana \\ ${ }^{3}$ School of Veterinary Medicine, University of Ghana, Accra, Ghana \\ ${ }^{4}$ Department of Clinical Microbiology, School of Medical Science, Kwame Nkrumah University of Science and Technology, \\ Kumasi, Ghana \\ Email: ojukwu.ken@gmail.com, chabijoseph@yahoo.fr, kfrempong@noguchi.ug.edu.gh, dellie1948@gmail.com, \\ josei@noguchi.ug.edu.gh, AAsafu-Adjaye@noguchi.ug.edu.gh, SPi-Bansa@noguchi.ug.edu.gh, \\ madimazoya@noguchi.ug.edu.gh, ksakyi@noguchi.ug.edu.gh, kakouko@noguchi.ug.edu.gh, carrebren@yahoo.com, \\ mappawu@noguchi.ug.edu.gh, *sdadzie@noguchi.ug.edu.gh
}

How to cite this paper: Ojukwu, K.C., Chabi, J., Frempong, K., Adabie-Gomez, D.A., Osei, J.H.N., Asafu-Adjaye, A., Pi-Bansa, S., Adimazoya, M., Sakyi, K.Y., Akuoko, K.O., Brenyah, R., Appawu, M.A. and Dadzie, S.K. (2022) Ecology, Distribution and Risk of Transmission of Viral Haemorrhagic Fevers by Aedes Mosquitoes around the Port Areas of Tema in Southern Ghana. Advances in Entomology, 10, 135-148.

https://doi.org/10.4236/ae.2022.102010

Received: April 2, 2018

Accepted: February 8, 2022

Published: February 11, 2022

\begin{abstract}
Aedes-borne diseases remain a public health challenge for many countries globally. The extent of spread of invasive species of Aedes mosquitoes and risk of transmission of the diseases especially around the point of entry of goods such as ports is not well known in Ghana. This study investigated the ecology, distribution and risk of transmission of viral haemorrhagic fevers by Aedes mosquitoes around the port areas of Tema, Southern Ghana. The mosquitoes from this study were collected using human landing catches, ovitraps and larval collections for a period of six months. A total of 1092 containers were inspected in both seasons and of these, 237 (21.7\%) were positive for mosquito larvae or pupae in rainy season while 181 (16.6\%) were positive in dry season. A total of 6498 mosquitoes were collected and identified morphologically using taxonomic keys. 6038 (92.9\%) were Aedes aegypti, 337 (5.2\%) were Culex spp. and 123 (1.9\%) were Anopheles gambiae. The Ae. aegypti larvae were found breeding in a series of water-holding containers which included disposed plastic containers, earthenware pots, car tyres, plastic barrels, plastic basins, buckets, metal drums, jerrycans and poly tank. A
\end{abstract}


Copyright $\odot 2022$ by author(s) and Scientific Research Publishing Inc. This work is licensed under the Creative Commons Attribution International License (CC BY 4.0).

http://creativecommons.org/licenses/by/4.0/

Open Access high proportion of Aedes aegypti eggs were found in the ovitraps during the rainy season than in the dry season in the study sites. Ae. aegypti was the most common mosquitoes biting mostly outdoors (65.6\%) with more bites occurring in the rainy season (63.6\%) in the two residential sites (Tema Community One and Tema New Town). The risk of transmission of viral haemorrhagic fever in the study sites was assessed using House Index, Container Index, Breteau Index and was found to be higher in Tema New town area with seasonal variations within the sites. The man-vector contact rates for the two residential sites were also found to be higher in rainy season than the dry season. These observations indicate that the risk of transmission of viral haemorrhagic fevers in the study areas is high especially in the rainy season. The implications of the findings in the formulation of future vector control programmes around the port areas in the country are discussed in the paper.

\section{Keywords}

Viral Haemorrhagic Fevers, Tema Port Areas, Aedes, Risk of Transmission

\section{Introduction}

Aedes mosquitoes (Diptera: Culicidae) are known to occur in the tropics and subtropics although currently, they have been established in all parts of the world with the exception of Antarctica [1] [2] thus allowing the entry and epidemics of viruses into new populations of susceptible human hosts. Various species in this genus are found in different parts of the world with distribution into new geographical limits made possible by international trade and various human activities. This is the case with Aedes albopictus which is a zoophilic Southeast Asian species currently introduced into various countries via importation of dormant or inactive viable eggs in fairly used tyres [3] [4]. Aedes mosquitoes have been reported to breed in various sites which include discarded cans, earthenware pots, tree holes, rock pools, crab burrows, car tyres, etc.

Some species in this genus transmit arthropod-borne viruses of public health importance including dengue fever, yellow fever, rift valley fever, Venezuelan equine encephalitis, Japanese encephalitis, zika, la Crosse viruses and chikungunya [5] [6] which negatively impact the economy of many countries. Human activity such as international shipping of goods has been known to expand the distribution of Aedes aegypti and Ae. albopictus [7]. It is also known that the spread of the container-breeding species Ae. albopictus and Ae. aegypti beyond their native range has been facilitated by the trade of goods, significantly in used tyres and machinery through the land and sea ports [8] [9] [10].

Yellow fever is known to be endemic in Ghana and the major outbreak that happened in the country between 1969-1970 in Damongo and Pong-Tamale in the Northern Region, Bolgatanga and Navrongo in the Upper East Region, and Nandom and Jirapa in the Upper West Region recorded 319 cases with 79 deaths [11]. 
Although not much transmission of arboviruses has been reported in the country, there are reports of arboviruses such as Dengue circulating in Ghana [12] [13] which borders Côte d'Ivoire and Burkina Faso where outbreaks have been documented [14] [15]. Ae. albopictus has also been documented to be present in southern Ghana [16]. This species has been documented in Gabon as the main vector for Zika Virus is currently known to be spreading to countries in West Africa [17]. This prompts the apt need for vector surveillance especially at the port areas since it has been documented that the main route of introduction of this species to countries has been through the importation of used tyres [18].

Also, considering the increased migration of people across borders of countries, unchecked international trade and the absence of organized mosquito control programme, there is the need to generate comprehensive information on Aedes vectors of Dengue and other viral hemorrhagic fevers especially around the port areas in the country. The objective of this study was to determine the ecology and distribution of Aedes mosquitoes as well as assess the risk of transmission of viral haemorrhagic fevers around the port areas in Tema.

\section{Materials and Methods}

\subsection{Study Areas}

The study was carried out in areas around the Tema Port which comprises Tema Community One $\left(5.64574^{\circ} \mathrm{N}, 0.00235^{\circ} \mathrm{E}\right.$ and $\left.24 \mathrm{~m}\right)$, Tema New Town $\left(5.6530^{\circ} \mathrm{N}, 0.0252^{\circ} \mathrm{E}\right.$ and $\left.24 \mathrm{~m}\right)$ and Golden Jubilee Terminal of Tema Seaport $\left(5.6246^{\circ} \mathrm{N}, 0.01187^{\circ} \mathrm{E}\right.$ and $23 \mathrm{~m}$ ) (Figure 1). The collections were carried out during the wet (October-November and April) and dry (January-March) seasons of 2016 and 2017. These areas are all in Tema, which is a large settlement located on the Gulf of Guinea and Atlantic shore of Ghana. It is situated around 30 kilometres east of the capital city, Accra, in the Greater Accra Region. Tema is characterized by a dry equatorial climate lying in the coastal savannah zone. It is found in the arid part of Southern Ghana, experiencing normal yearly rainfall of around 750 millimetres [19]. The inhabitants of the study areas work in the Tema port, the fishing harbour and other industries in Tema, while some are self-employed or are engaged in elementary occupations such as road-side hawking of snacks or soft drinks while the aged ones who cannot work always stay at home throughout the day. This is a typical urban settlement although some structures are typical of those which can be found in a rural settlement.

\subsection{Household Mosquito Larval Surveys}

A house-to-house entomological survey was carried out in houses and peri-domestic areas in each of the study area using a simple random sampling method. Each house selected was examined to detect mosquito larval breeding sites. Water storage containers and tyres (imported and those at vulcanizer shops) 


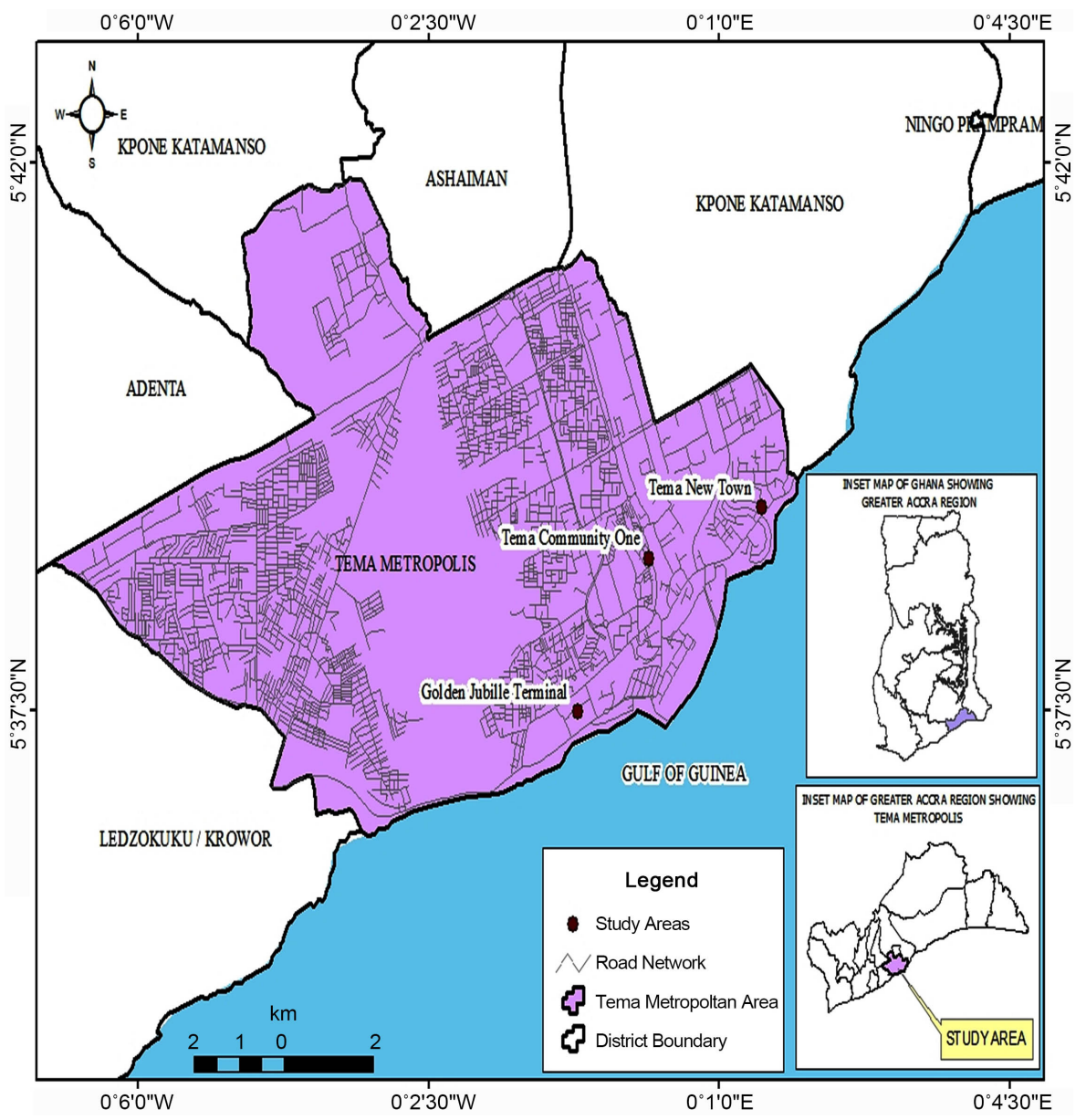

Figure 1. Map of Ghana showing Tema Metropolis and the three study sites.

were inspected for the presence of pre-adult stages of Aedes mosquitoes for larval indices estimation. Each container was recorded for container type, location within the house and sun exposure. Mosquito larvae and pupae were collected from used tyres and other artificial containers with a $350 \mathrm{~m}$ ladle, pipette or scooper into a well labeled transparent water holding containers which were covered with perforated lid to provide aeration. A torch light was used for visibility in dark containers and dark rooms.

\subsection{Oviposition Traps}

Ovitraps were randomly set at strategic points at each study site. They were placed at concealed places to prevent being tampered with by the inhabitants. These traps were set in order to detect the presence and to estimate population density of Aedes mosquitoes during the rainy and dry season. The ovitraps consist of small plastic containers which were modified by placing a wooden paddle inside the ovitraps to serve as landing base/support for ovipositing female mosquitoes and by baiting them with grasses and a pinch of larvae feed (TetraMin ${ }^{\circledR}$ fish flakes) which gave a conducive breeding site for Aedes larvae. These traps were observed every three days for a month and all the eggs or any hatched im- 
mature stages found in the ovitraps were emptied into well-labeled transparent water-holding containers and reared into adults.

\subsection{Estimation of Man-Vector Contact Rates}

Hourly collections of adult female Aedes mosquitoes were done to determine diurnal biting patterns of Aedes mosquitoes prevalent in two of the study sites (Tema Community One and Tema New Town). This was carried out from 15:00 to 18:00 hrs GMT. This exercise was carried out both indoors and outdoors in selected places in two of the study sites during the rainy and dry seasons. Four collectors (two indoors and the other two outdoors) were involved in this collection exercise. All adult female mosquitoes which landed on the exposed skin of the limbs of the collectors to bite were collected using a $15 \mathrm{ml}$ falcon tubes and transferred into well labeled sealed paper cups, killed with chloroform and left for identification. For each season, a total of 48 man-hours were used to carry out the landing catches both indoors and outdoors.

\subsection{Species Identification}

All eggs, larvae and pupae of mosquitoes collected were incubated to adult stages at the insectary of Noguchi Memorial Institute of Medical Research (NMIMR) and identified to species level under a microscope, using identification keys [20] [21].

\section{Data Analysis}

Data collected were input into Microsoft Excel and analyzed using SPSS 23.0 statistical software package. Pearson's Chi-square was used to test for association between variables, while the t-test was used to compare data for significant difference.

To estimate the risk of transmission of viral haemorrhagic fevers at the study sites, three larval indices were calculated. These are House index (HI), Container index (CI) and Breteau index (BI). HI was expressed as the percentage of houses infested with Aedes larvae; CI as the percentage of containers infected with larvae or pupae; and BI as the number of positive containers per 100 inspected houses.

The risk of transmission of Viral Haemorrhagic Fevers (VHFs) at the study site was estimated using the WHO criteria as follows: 1) An area where BI, HI, and CI exceeded 50, 35 and 20 respectively, the risk of Aedes mosquitoestransmitted VHF's was be considered to be high. 2) An area where BI is between 5 and 50, the density of Aedes mosquitoes was considered to be sufficient enough to promote an outbreak of VHF disease. 3) An area where BI, HI and CI were less than 5, 4 and 3 respectively, was considered to be unlikely for VHF transmission to occur [22] [23]. The man-vector contact (man biting rate) was assessed by the number of biting adult female Aedes mosquitoes per man-hour. Man-vector count exceeding two female bites per man-hour was also indicative 
of a significant risk of transmission of the disease [23]. Ovitrap index (OI) expressed as the percentage of traps infested with Aedes immature stages was also calculated for each site.

\section{Results}

\subsection{Species Composition and Ovitrap Index}

A total of 404 houses (240 at Tema Community One, 150 at Tema New Town and 14 at Golden Jubilee Terminal) were surveyed during the study period for the presence of immature Aedes in water holding containers in the various study sites. Out of the total number of houses surveyed, $122(30.2 \%)$ were positive for Aedes larvae.

A total of 6498 mosquitoes were collected from the three study using ovitraps, larval and human landing collections during the period of survey. A higher number, 5715 (88.0\%) of Aedes mosquitoes were collected from during the larval surveys, compared to 574 (8.8\%) from ovitraps and 209 (3.2\%) from human landing catches. Of the 6498 mosquitoes collected, 6038 (92.9\%) were Aedes aegypti, while Culex spp. and Anopheles gambiae constituted 5.2\% (337) and 1.9\% (123) respectively. Majority, 3053 (47\%) and 3057 (47\%) were collected from Tema Community One and Tema New Town respectively compared to 388 (6\%) from Golden Jubilee Terminal area. The ovitrap index ranged from 2.5 to 12.5 with the highest index recorded at the Golden Jubilee Terminal (Figure 2). The ovitrap index was generally high in the rainy season compared to the dry season.

\subsection{Larval Indices}

Larval indices estimated as House Index (HI), Container Index (CI) and Breteau Index (BI) varied in all the sites. Tema New Town recorded the highest indices compared to Tema Community One and Golden Jubilee Terminal. The HI, CI, BI estimated were respectively as follows Tema Community One (34.2, 39.4 and 108.3 for rainy and 23.3, 31.7 and 82.5 for dry season), Tema New Town (41.3, 44.9 and 134.7 for rainy and 28, 40.6 and 109.3 for dry season) and Golden Jubilee Terminal (14.3, 28.6 and 85.7 for rainy and 0 for all in dry season) as shown in Table 1. Seasonal variations in the larval indices observed were generally higher during the rainy season than the dry season.

\subsection{Prevalence of Aedes Larvae in Containers}

Out of the 1092 breeding containers inspected, 418 (38.3\%) were positive with $237(21.7 \%)$ positive for mosquito larvae or pupae in rainy season while 181 (16.6\%) were positive in dry season. These were $8(1.9 \%)$ earthenware pots, 1 (0.2\%) disposed plastic container, 96 (23.0\%) plastic barrels, 205 (49.0\%) plastic basins, $14(3.4 \%)$ buckets, $2(0.5 \%)$ poly tank, $62(14.8 \%)$ car tyres, $27(6.5 \%)$ metal drums and $3(0.7 \%)$ jerrycans (Figure 3$)$. Most of these water holding containers were located outdoors $(58.1 \%)$ while $62.8 \%$ of these breeding con- 
tainers were shaded or not exposed to the sun. Larvae and pupae of mosquitoes $(5,715)$ were found in the above-mentioned breeding containers inspected but mosquitoes preferred to breed in plastic basins (39.0\%), plastic barrels (23.3\%), car tyres (17.2\%), metal drums (8.1\%), earthenware pots (5.3\%) and poly tank (4.4\%) as compared to buckets, jerrycans and disposed plastic container as shown in Table 2 . The association between breeding sites and mosquito species was statistically significant $(P<0.001) .3713(65 \%)$ of these mosquitoes were collected in the rainy season and 2002 (35\%) collected in the dry season.

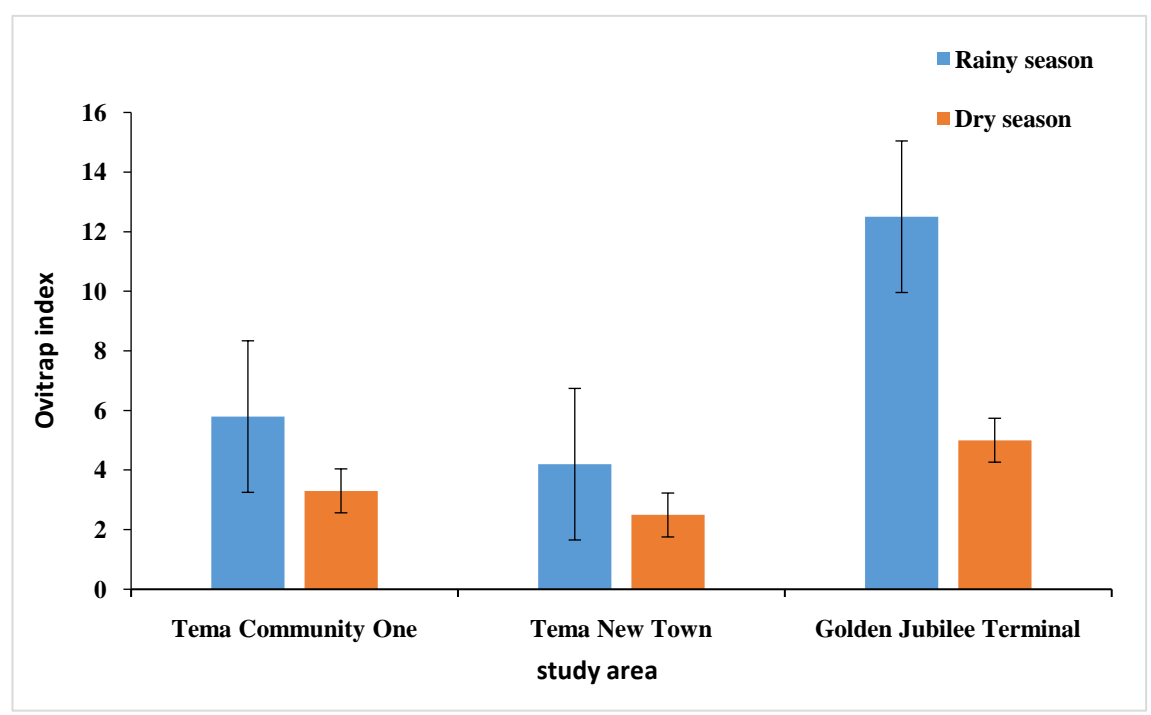

Figure 2. Ovitrap index estimated at the three study sites.

Table 1. Aedes mosquito larval indices for the three sites in the study area.

\begin{tabular}{|c|c|c|c|c|}
\hline $\begin{array}{c}\text { Entomological indices } \\
\text { by study sites }\end{array}$ & $\begin{array}{l}\text { Rainy } \\
\text { season }\end{array}$ & $\begin{array}{l}\text { Dry } \\
\text { season }\end{array}$ & $\begin{array}{c}\text { WHO Threshold for } \\
\text { transmission risk of } \\
\text { VHF's }\end{array}$ & $\begin{array}{l}\text { Level } \\
\text { of risk }\end{array}$ \\
\hline \multicolumn{5}{|l|}{ Tema Community One } \\
\hline House Index & 34.2 & 23.3 & $4-35$ or above & High \\
\hline Container Index & 39.4 & 31.7 & 3 - 20 or above & High \\
\hline Breteau Index & 108.3 & 82.5 & 5 - 50 or above & Very High \\
\hline \multicolumn{5}{|l|}{ Tema New Town } \\
\hline House Index & 41.3 & 28.0 & $4-35$ or above & High \\
\hline Container Index & 44.9 & 40.6 & $3-20$ or above & High \\
\hline Breteau Index & 134.7 & 09.3 & 5 - 50 or above & Very High \\
\hline \multicolumn{5}{|l|}{ Golden Jubilee Terminal } \\
\hline House Index & 14.3 & 0 & $4-35$ or above & High \\
\hline Container Index & 28.6 & 0 & $3-20$ or above & High \\
\hline Breteau Index & 85.7 & 0 & $5-50$ or above & High \\
\hline
\end{tabular}



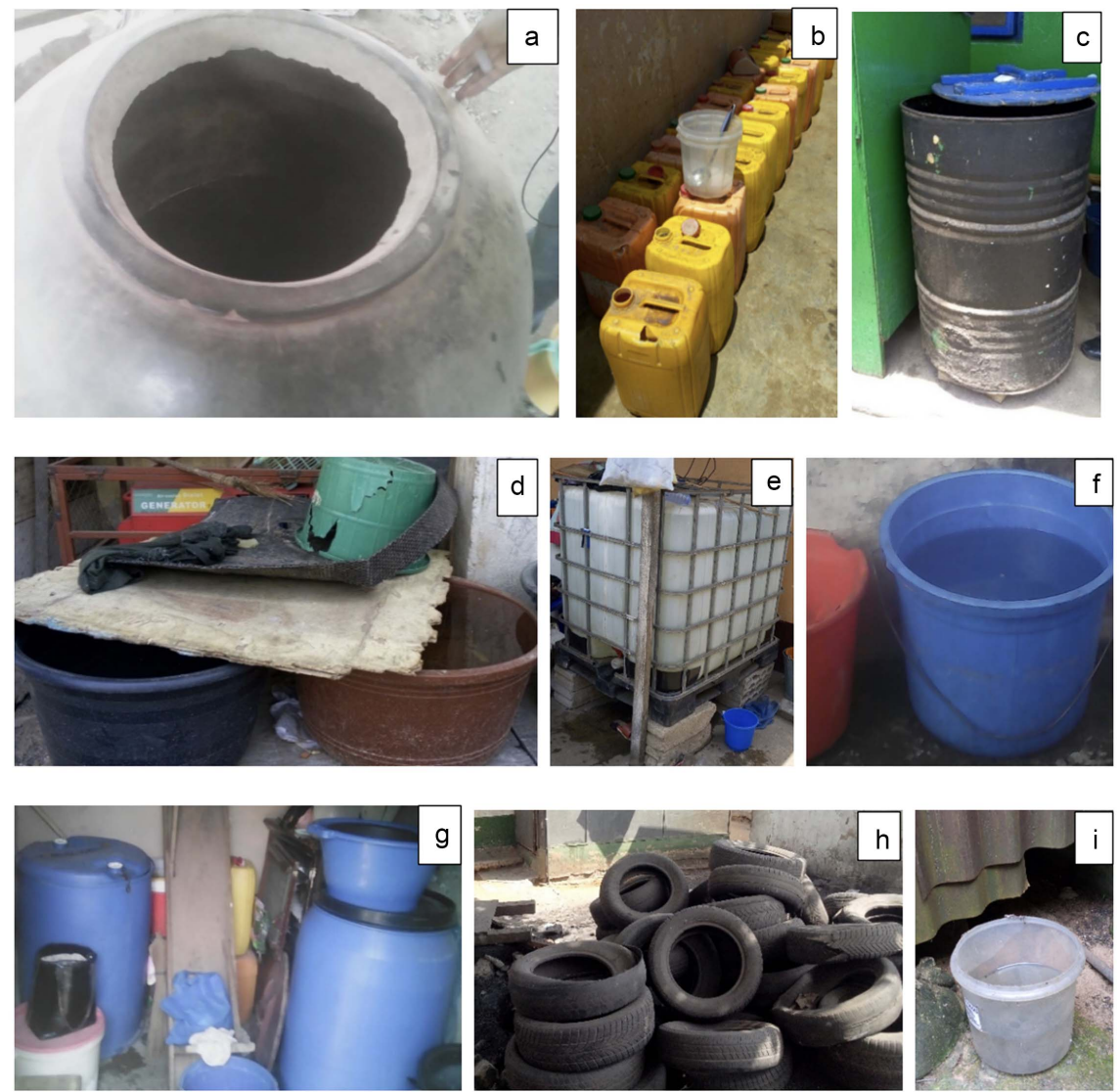

Figure 3. Mosquito larvae/pupae breeding sites: (a) earthenware pot, (b) jerrycan, (c) metal drum, (d) plastic basin, (e) poly tank, (f) bucket, (g) plastic barrel, (h) car tyre, (i) disposed plastic container.

Table 2. Number of mosquito larvae from the nine breeding containers.

\begin{tabular}{lccccc}
\hline & & \multicolumn{5}{c}{ Species } \\
\cline { 3 - 5 } No. & Breeding Sites & $\begin{array}{c}\text { Aedes aegypti } \\
\mathrm{n}(\%)\end{array}$ & $\begin{array}{c}\text { Culex spp. } \\
\mathrm{n}(\%)\end{array}$ & $\begin{array}{c}\text { Anopheles gambiae } \\
\mathrm{n}(\%)\end{array}$ \\
\hline 1. & $\begin{array}{c}\text { Earthenware } \\
\text { pots }\end{array}$ & $301(5.3)$ & 0 & 0 & $301(5.3)$ \\
2. & Car tyres & $765(13.4)$ & $159(2.8)$ & $61(1.1)$ & $985(17.2)$ \\
3. & $\begin{array}{c}\text { Disposed plastic } \\
\text { container }\end{array}$ & $21(0.4)$ & 0 & 0 & $21(0.4)$ \\
4. & Plastic barrels & $1226(21.5)$ & $62(1.1)$ & $45(0.8)$ & $1333(23.3)$ \\
5. & Plastic basins & $2110(36.9)$ & $116(2)$ & 0 & $2226(39.0)$ \\
6. & Buckets & $107(1.9)$ & 0 & 0 & $107(1.9)$ \\
7. & Jerrycans & $25(0.4)$ & 0 & 0 & $25(0.4)$ \\
8. & Metal drums & $465(8.1)$ & 0 & 0 & $465(8.1)$ \\
9. & Poly tank & $252(4.4)$ & 0 & 0 & $252(4.4)$ \\
& Total & 5272 & 337 & 106 & 5715 \\
\hline
\end{tabular}




\subsection{Adult Biting Activity and Man-Vector Contact Rate}

A total of 209 adult Aedes mosquitoes were collected out of which 133 and 76 were collected during the rainy season and dry season respectively for the two study sites. Ae aegypti was identified as the only mosquito biting in the study sites. More collections of mosquitoes were made outdoors compared to indoors [Tema Community One $=39(18.7 \%)$ indoors and $71(34.0 \%)$ outdoors; Tema New Town $=33(15.8 \%)$ indoors and $66(31.6 \%)$ outdoors] There was significant differences between mosquitoes caught indoors and outdoors in the two communities [Tema Community One $(P<0.001)$; Tema New Town $(P<0.001)$ ]. However, from the hourly collections of adult mosquitoes made, highest collections were made from the hours of 17:00-18:00 GMT (Tema Community One = 69; Tema New Town $=67$ ) followed by the hours of 16:00-17:00 (Tema Community One $=32$; Tema New Town $=24)$. Least collections were made between the hours of 15:00-16:00 (Community One $=9$; Tema New Town $=8$ ). The man vector rates was generally higher during the rainy season than the dry season. The man-vector contact rates for the two residential sites were 1.5 and 0.8 bites per man hour in rainy season and dry season respectively for Tema Community One and 1.3 and 0.8 bites per man hour in rainy season and dry season for Tema New Town. Figure 3 shows the ovitrap index estimated for the three sites. The ovitrap index was highest in Golden Jubilee terminal.

\section{Discussion}

Different species of Aedes mosquitoes, which are potential vectors for yellow fever, are already known to be distributed all over Ghana as reported by various studies in different parts of the country [11] [16] [24] [25]. The study revealed the presence of only one distinct Aedes species and other mosquito species ( $\mathrm{Cu}$ lex spp. and Anopheles gambiae) which are not relevant to this study in the Port areas of Tema. The predominant Aedes species encountered or recorded in this study was Aedes aegypti. This could be a result of the urban nature of Tema. This species has been reported to be the dominant species in densely crowded urban areas [26] [27] where they serve as potential vector for the urban cycle of yellow fever transmission [28]. This mode of transmission is made more possible because of the domestic characteristics of the species wherein they live in close proximity and association with humans.

However, in most urban dwellings, tap and rain water are stored in varying containers which include plastic barrels, buckets and plastic basins due to irregular supply of water [29]. Containers which retain or hold water for longer periods of time serve as potential breeding sites for mosquitoes [30]. In the two residential communities close to the port of Tema where part of the study was also carried out, even in the presence of pipe borne water, water is stored in basins in most households due to intermittent pattern of water supply which is most common in the rainy season compared to the dry season. The study area had different sites that favoured the breeding of Aedes mosquitoes which also 
resulted in the high larval indices recorded. It was observed that more mosquitoes were breeding in basins followed by plastic barrels and car tyres amongst other types breeding sites. This is may be due to the frequent usage of plastic basins for water storage by various households. Ae. aegypti mosquitoes were the dominant species obtained from all the different types of breeding containers followed by Culex spp. and An. gambiae. Ae. aegypti, Culex spp. and An. gambiae which were mostly found in close association with car tyres and plastic barrels. The presence of these mosquitoes in car tyres has also been reported in other studies [27] [31].

In the study, more car tyres and disposed containers were recorded to collect water. This could have triggered the hatching of eggs of Aedes mosquitoes laid during the previous dry season owing to the fact that Aedes eggs can withstand long periods of desiccation thus contributing to the high number of mosquitoes during the rainy season [32].

Temperature, relative humidity and nutrients source is known to contribute to mosquito abundance during rainy season, while absence of all or any of these components and high or extreme temperature decrease mosquito breeding or abundance in the dry season [33]. In this study, high abundance of Aedes immature stages were found in the rainy season than the dry season as previously reported in other studies in northern and southern Ghana [16] [24] [25]. However, another study in northern Ghana found high larval indices in the dry season than the rainy season and ascribed the reason that many people tend to store water much longer during the dry season than the rainy season [34]. Water availability and use has been associated with the breeding of Aedes immature stages [34]. Availability and ready access to pipe-borne water reduced the practice of storing water in containers for long periods necessary to allow the breeding of Aedes mosquitoes. In this study, more containers had water collected in them in the rainy season compared to numbers recorded in the dry season. The study area is much urban and most households have ready access to pipe-borne water even in the dry season. It can therefore be postulated that high prevalence of Aedes immature stages in the area could be due to the availability of water during the rainy season. The recent WHO-TDR document [35] on the use of multisectoral approaches for controlling vector-borne diseases highlights the need for collaboration between the water hygiene and sanitation sector (WASH) and disease control programs to help support the formulation of future control strategies.

Adult Aedes species are day time biters preferring to feed during the day or early evening. They usually bite and rest outdoors before and after feeding [23] [36]. From this study, it was observed that more mosquitoes were biting outdoors as compared to indoors. This situation in the study area may be attributed to the several breeding sites found around houses than inside as more breeding containers were recorded outside houses than inside in this study. The study also revealed that Ae. aegypti, which was the only species recorded from human landing catches, starts biting in the afternoon and peaking around the hours of 
17:00-18:00 GMT. These findings are very significant and important for the formulation of future vector control programmes around these areas. The intensity of disease transmission therefore will be expected to be higher around the hours of 17:00-18:00 GMT. Therefore, the use of several protective measures against the bites of Aedes mosquitoes at these times of the day could reduce the transmission of arboviruses in the area.

Use of ovitraps was also helpful for surveillance of Aedes species in the study areas as they assisted in the determination of presence, abundance and distribution of the dengue vectors. It is also an important tool or surveillance method for providing spatial distribution and temporary data for monitoring and assessing the impact of control measures [37]. The relatively high number of Ae. aegypti collected using this method in this study was probably due to the fact that $A e$. aegypti mosquitoes are container loving mosquitoes which show high affinity to oviposit in any suitable water holding container which has held water for a long time [38] [39].

\section{Conclusion}

The results from the larval indices indicate that Aedes population in the study sites was sufficient enough to promote outbreak of yellow fever or any VHF prompting the establishment of a mosquito control programme in the study area. Inhabitants of the two residential communities should be encouraged to use mosquito repellent when outside between 17:00-18:00 hrs GMT (the peak biting time of the species), while water storage containers kept both inside and outside houses should be emptied regularly to reduce mosquito breeding sources. Although Ae. albopictus was not found during the current survey, a previous study identified the species to be present in some areas in southern Ghana where the port is located. The extent of spread of this species in the country is not well known and it calls for more enhanced vector surveillance as well proper sanitation and waste disposal should be carried out in the area to prevent or control the introduction of invasive species into the country.

\section{Data Availability}

The datasets used during the current study are available from the corresponding author on reasonable request.

\section{Author's Contributions}

KCO conducted the fieldwork and data analysis and drafted the manuscript; JC, JNO, AAA, SPB, MA, KY, KOA assisted in laboratory work and data analysis; DAG, MAA, RB supervised the work and edited the manuscript; SD designed the study, supervised data analysis and edited the manuscript.

\section{Acknowledgements}

The authors gratefully thank the members of the Vector Research Group of the 
Parasitology Department of the Noguchi Memorial Institute for Medical Research, Ghana and all staff of the Port Health Division of the Ghana Health Service, Ghana.

\section{Conflicts of Interest}

The authors declare no conflicts of interest regarding the publication of this paper.

\section{References}

[1] Gordon, R.M. and Lavoipierre, M.M.J. (1976) The Tribe Culicini and Its Division into Five Groups of Related Genera. In: Entomology for Students of Medicine, Cambridge University Press, Cambridge, 117.

[2] Service, M.W. (1980) Culicine Mosquitoes (Order Diptera: Family Culicidae, Subfamily Culicinae). In: Service, M.W., Ed., A Guide to Medical Entomology, The Macmillan Press Ltd., Hong Kong, 56. https://doi.org/10.1007/978-1-349-16334-2_6

[3] Gratz, N.G. (2004) Critical Review of the Vector Status of Aedes albopictus. Medical and Veterinary Entomology, 18, 215-227. https://doi.org/10.1111/j.0269-283X.2004.00513.x

[4] Reiter, P. (1998) Aedes albopictus and the World Trade in Used Tires, 1988-1995: The Shape of Things to Come? Journal of the American Mosquito Control Association, 14, 83-94.

[5] Gubler, D.J., Kuno, G. and Markoff, L. (2007) Flaviviruses. Fields Virology, 1, 1153-1253.

[6] Weaver, S.C. and Reisen, W.K. (2010) Present and Future Arboviral Threats. Antiviral Research, 85, 328-345. https://doi.org/10.1016/j.antiviral.2009.10.008

[7] Powell, J.R. and Tabachnick, W.J. (2013) History of Domestication and Spread of Aedes aegypti-A Review. Memorias do Instituto Oswaldo Cruz, 108, 11-17. https://doi.org/10.1590/0074-0276130395

[8] Enserink, M.A. (2008) Mosquito Goes Global. Science, 320, 864-866. https://doi.org/10.1126/science.320.5878.864

[9] Scholte, E.-J. and Schaffner, F. (2007) Chapter 14. Waiting for the Tiger: Establishment and Spread of the Aedes albopictus Mosquito in Europe. In: Emerging Pests and Vector-Borne Diseases in Europe, Wageningen Academic Publishers, Wageningen, Volume 1, 241.

[10] DeHart, R.L. (2003) Health Issues of Air Travel. Annual Review of Public Health, 24, 133-151. https://doi.org/10.1146/annurev.publhealth.24.100901.140853

[11] Agadzi, V.K., Boatin, B.A., Appawu, M.A., Mingle, J.A.A. and Addy, P.A. (1984) Yellow Fever in Ghana, 1977-1980. Bulletin of the World Health Organization, 62, 577-583.

[12] Amoako, N., Duodu, S., Dennis, F.E., Bonney, J.H.K., Asante, K.P., Ameh, J., et al. (2018) Detection of Dengue Virus among Children with Suspected Malaria, Accra, Ghana. Emerging Infectious Diseases, 24, 1544-1547. https://doi.org/10.3201/eid2408.180341

[13] Bonney, J.H.K., Hayashi, T., Dadzie, S., Agbosu, E., Pratt, D., Nyarko, S., et al. (2018) Molecular Detection of Dengue Virus in Patients Suspected of Ebola Virus Disease in Ghana. PLOS ONE, 13, e0208907. https://doi.org/10.1371/journal.pone.0208907 
[14] World Health Organization (WHO) (1995) Report of the Consultation on Key Issues in Dengue Vector Control towards the Operationalization of a Global Strategy. WHO CTD/FIL (DEN)/IC/96.1, Geneva, 48.

[15] World Health Organization (WHO) (2009) Dengue: Guidelines for Diagnosis, Treatment, Prevention and Control. WHO/CDS/(DEN)/IC/2000.1, Geneva, 20.

[16] Suzuki, T., Osei, J.H.N., Sasaki, A., Adimazoya, M., Appawu, M., Boakye, D., et al. (2016) Risk of Transmission of Viral Haemorrhagic Fevers and the Insecticide Susceptibility Status of Aedes aegypti (Linnaeus) in Some Sites in Accra, Ghana. Ghana Medical Journal, 50, 136-141. https://doi.org/10.4314/gmj.v50i3.4

[17] Grard, G., Caron, M., Mombo, I.M., Nkoghe, D., Ondo, S.M., Jiolle, D., Fontenille, D., Paupy, C. and Leroy, E.M. (2014) Zika Virus in Gabon (Central Africa)-2007: A New Threat from Aedes albopictus? PLOS Neglected Tropical Diseases, 8, e2681. https://doi.org/10.1371/journal.pntd.0002681

[18] Reiter, P. (1993) Problems in the Use of ULV Sprays for the Control of Aedes aegypti an Urban Mosquito. In: Wildey, K.B. and Robinson, W.H., Eds., Proceedings of the 1st International Conference on the Insect Pests in the Urban Environment (ICIPUE93), BPCC Wheatons Ltd., Exeter, 44.

[19] Tema Metropolitan, Archived November 2010 at the Wayback Machine. Ghana Districts.com.

[20] Huang, Y.M. (2004) The Subgenus Stegomyia of Aedes in the Afrotropical Region with Keys to the Species (Diptera: Culicidae) Magnolia Press, Auckland, New Zealand. Zootaxa, 700, 1-120. https://doi.org/10.11646/zootaxa.700.1.1

[21] Rueda, L.M. (2004) Zootaxa 589: Pictorial Keys for the Identification of Mosquitoes (Diptera: Culicinidae) Associated with Dengue Virus Transmission. Magnolia Press, Auckland, 60 p. https://doi.org/10.11646/zootaxa.589.1.1

[22] World Health Organization (WHO) (1971) Technical Guide for a System of Yellow Fever Surveillance. The Weekly Epidemiological Record, 46, 493-500.

[23] World Health Organization (WHO) (1986) Prevention and Control of Yellow Fever in Africa. WHO, Geneva, 1-89.

[24] Captain-Esoah, M., Baidoo, P.K., Frempong, K.K., Adabie-Gomez, D., Chabi, J., Obuobi, D., Amlalo, G.K., Veriegh, F.B., Donkor, M., Asoala, V., Behene, E., Boakye, D.A. and Dadzie, S.K. (2020) Biting Behavior and Molecular Identification of Aedes aegypti Subspecies in Some Selected Recent Yellow Fever Outbreak Communities in Northern Ghana. Journal of Medical Entomology, 29, 1239-1245. https://doi.org/10.1093/jme/tjaa024

[25] Joannides, J., Dzodzomenyo, M., Azerigyik, F., Agbosu, E.E., Pratt, D., Osei, J.H.N., Pwalia, R., Amlalo, G., Appawu, M., Takashi, H., Iwanaga, S., Buchwald, A., Rochford, R., Boakye, D., Koram, K., Bonney, K. and Dadzie, S.K. (2021) Species Composition and Risk of Transmission of Some Aedes-Borne Arboviruses in Some Sites in Northern Ghana. PLoS ONE, 16, e0234675.

https://doi.org/10.1371/journal.pone.0234675

[26] Delatte, H., Dehecq, J.S., Thiria, J., Domerg, C., Paupy, C. and Fontenille, D. (2008) Geographic Distribution and Developmental Sites of Aedes albopictus (Diptera: Culicidae) during a Chikungunya Epidemic Event. Vector-Borne and Zoonotic Diseases, 8, 25-34. https://doi.org/10.1089/vbz.2007.0649

[27] Getachew, D., Tekie, H., Gebre-Michael, T., Balkew, M. and Mesfin, A. (2015) Breeding Sites of Aedes aegypti: Potential Dengue Vectors in Dire Dawa, East Ethiopia. Interdisciplinary Perspectives on Infectious Diseases, 2015, Article ID: 706276. https://doi.org/10.1155/2015/706276 
[28] Vainio, J. and Cutts, F. (1998) Yellow Fever. World Health Organization, Geneva, WHO/EPI/GEN/98, 11, 1-87.

[29] Bhat, M.A. and Krishnamoorthy, K. (2014) Entomological Investigation and Distribution of Aedes Mosquitoes in Tirunelveli, TamilNadu, India. International Journal of Current Microbiology Application Sciences, 3, 253-260.

[30] Saleeza, S.N.R., Norma-Rashid, Y. and Sofian-Azirun, M. (2011) Mosquitoes Larval Breeding Habitat in Urban and Suburban Areas, Peninsular Malaysia. International Journal of Biological Veterinary, Agricultural and Food Engineering, 5, 81-85.

[31] Joy, J.E., Hanna, A.A. and Kennedy, B.A. (2003) Spatial and Temporal Variation in the Mosquitoes (Diptera: Culicidae) Inhabiting Waste Tires in Nicholas County, West Virginia. Journal of Medical Entomology, 40, 73-77. https://doi.org/10.1603/0022-2585-40.1.73

[32] Schultz, G.W. (1993) Seasonal Abundance of Dengue Vectors in Manila, Republic of the Philippines. Southeast Asian Journal of Tropical Medicine and Public Health, 24, 369-375.

[33] Service, M.W. (1974) Survey of the Relative Prevalence of Potential Yellow Fever Vectors in North-West Nigeria. Bulletin of the World Health Organization, 50, 487-494.

[34] Appawu, M., Dadzie, S., Abdul, H., Asmah, H., Boakye, D., Wilson, M. and Ofori-Adjei, D. (2006) Surveillance of Viral Haemorrhagic Fevers in Ghana: Entomological Assessment of the Risk of Transmission in the Northern Regions. Ghana Medical Journal, 40, 137-141. https://doi.org/10.4314/gmj.v40i3.55269

[35] (2020) Multisectoral Approach for the Prevention and Control of Vector-Borne Diseases. World Health Organization, Geneva.

[36] Thavara, U., Tawatsin, A., Chansang, C., Kongngamsuk, W., Paosriwong, S., Boon-Long, J., Rongsriyam, Y. and Komalamisra, N. (2001) Larval Occurrence, Oviposition Behaviour and Biting Activity of Potential Mosquito Vectors of Dengue on Samui Island, Thailand. Journal of Vector Ecology, 23, 172-180.

[37] Serpa, L.L.N., Marques, G.R.A.M., de Lima, A.P., Voltolini, J.C., de Brito Arduino, M., Barbosa, G.L., Andrade, V.R. and de Lima, V.L.C. (2013) Study of the Distribution and Abundance of the Eggs of Aedes aegypti and Aedes albopictus According to the Habitat and Meteorological Variables, Municipality of Sao Sebastiao, Sao Paulo State, Brazil. Parasites \& Vectors, 6, Article No. 321. https://doi.org/10.1186/1756-3305-6-321

[38] Dejene, G., Habte, T., Teshome, G., Meshesha, B. and Akalu, M. (2015) Breeding Sites of Aedes aegypti: Potential Dengue Vectors in Dire Dawa, East Ethiopia. Interdisciplinary Perspectives on Infectious Diseases, 2015, Article ID: 70627. https://doi.org/10.1155/2015/706276

[39] Sharma, S.K., Padhan, K., Rath, Y. and Rao, S.K. (2001) Observations on the Breeding Habitat of Aedes Species in the Steel Township, Rourkela. The Journal of Communicable Diseases, 33, 28-35. 